\title{
RESEARCH
}

Open Access

\section{Effects of local neighbourhood diversity on crown structure and productivity of individual trees in mature mixed-species forests}

Louis Georgi ${ }^{1 *}$ (D) Matthias Kunz ${ }^{1}$, Andreas Fichtner ${ }^{2}$, Karl Friedrich Reich ${ }^{1}$, Anne Bienert ${ }^{3}$, Hans-Gerd Maas ${ }^{3}$ and Goddert von Oheimb ${ }^{1}$

\begin{abstract}
Background: Species-specific genotypic features, local neighbourhood interactions and resource supply strongly influence the tree stature and growth rate. In mixed-species forests, diversity-mediated biomass allocation has been suggested to be a fundamental mechanism underlying the positive biodiversity-productivity relationships. Empirical evidence, however, is rare about the impact of local neighbourhood diversity on tree characteristics analysed at a very high level of detail. To address this issue we analysed these effects on the individual-tree crown architecture and tree productivity in a mature mixed forest in northern Germany.

Methods: Our analysis considers multiple target tree species across a local neighbourhood species richness gradient ranging from 1 to 4 . We applied terrestrial laser scanning to quantify a large number of individual mature trees $(N=920)$ at very high accuracy. We evaluated two different neighbour inclusion approaches by analysing both a fixed radius selection procedure and a selection based on overlapping crowns.

Results and conclusions: We show that local neighbourhood species diversity significantly increases crown dimension and wood volume of target trees. Moreover, we found a size-dependency of diversity effects on tree productivity (basal area and wood volume increment) with positive effects for large-sized trees (diameter at breast height $(\mathrm{DBH})>40 \mathrm{~cm}$ ) and negative effects for small-sized $(\mathrm{DBH}<40 \mathrm{~cm})$ trees. In our analysis, the neighbour inclusion approach has a significant impact on the outcome. For scientific studies and the validation of growth models we recommend a neighbour selection by overlapping crowns, because this seems to be the relevant scale at which local neighbourhood interactions occur. Because local neighbourhood diversity promotes individual-tree productivity in mature European mixed-species forests, we conclude that a small-scale species mixture should be considered in management plans.
\end{abstract}

Keywords: Biodiversity, Tree growth, Crown architecture, Quantitative structure models, Terrestrial laser scanning, Neighbour classification

\footnotetext{
* Correspondence: louis.georgi@tu-dresden.de

${ }^{1}$ Technische Universität Dresden, Institute of General Ecology and Environmental Protection, Pienner Straße 7, 01737 Tharandt, Germany Full list of author information is available at the end of the article
}

\section{Springer Open}

(c) The Author(s). 2021 Open Access This article is licensed under a Creative Commons Attribution 4.0 International License, which permits use, sharing, adaptation, distribution and reproduction in any medium or format, as long as you give appropriate credit to the original author(s) and the source, provide a link to the Creative Commons licence, and indicate if changes were made. The images or other third party material in this article are included in the article's Creative Commons licence, unless indicated otherwise in a credit line to the material. If material is not included in the article's Creative Commons licence and your intended use is not permitted by statutory regulation or exceeds the permitted use, you will need to obtain permission directly from the copyright holder. To view a copy of this licence, visit http://creativecommons.org/licenses/by/4.0/. 


\section{Background}

Forest canopies play a decisive role in shaping the local and global climatic conditions due to evaporation and carbon fixation ( $\mathrm{Li}$ et al. 2015; Bastin et al. 2019), and constitute an important habitat for a multitude of species (Ozanne et al. 2003). Canopies are formed by crowns of individual trees, which strive for the optimisation of their own light access in order to maximize the photosynthesis potential. The crown architecture is of particular importance here, because of its direct link to a tree's light absorption (Ishii and Asano 2010; Sapijanskas et al. 2014; Forrester et al. 2018). While the fundamental architecture of the crown is embedded in the speciesspecific genotype (Costes and Gion 2015), the actual stature and allometry is strongly influenced by the local tree species composition and resource supply (De Kroon et al. 2005; Bayer et al. 2013; del Río et al. 2019). Besides abiotic factors, e.g. slope inclination (Lang et al. 2010), biotic interactions at the local level, e.g. crowding and species composition, are most crucial for the realized crown shape in closed-canopy stands (Pretzsch and Schütze 2009; Fichtner et al. 2013; Forrester et al. 2017). Photomorphogenetic responses of individual trees result in considerable crown plasticity, i.e. the environmentally driven intraspecific variability in crown architecture (Schröter et al. 2012; Pretzsch 2014). These light-related tree interactions for physical niche partitioning in canopy space have been found to be severely impacted by species mixing and are thought to be an important process in explaining the positive biodiversity - productivity relationships (BPRs) in forests (Morin et al. 2011; Huang et al. 2018; Kunz et al. 2019).

The diversity-driven modifications in the individualtree crowns are based on variations in crown size and shape (Pretzsch 2014; Williams et al. 2017; Kunz et al. 2019). The underlying mechanisms operate at multiple hierarchical levels, ranging from shifts in branch morphology and ramification to modifications in the biomass allocation ratio between trunk and branches (Kunz et al. 2019; Guillemot et al. 2020). However, empirical evidence is rare about the impact of local neighbourhood species richness on tree crown architecture analysed at a very high level of detail.

Such analyses, with a very high spatial resolution, can be carried out effectively making use of terrestrial laser scanning (TLS) (Liang et al. 2016). The few studies cited below which have been conducted with high-resolution TLS in mature forests of Central Europe mainly compared the effects between intra- and interspecific tree interactions in pure and mixed stands and/or focused on only one tree species, namely European beech (Fagus sylvatica L.). In addition, the gradient in the number of neighbouring tree species was often short. In comparison to pure stands, Bayer et al. (2013) observed larger crown volumes (CV) for beech and Norway spruce (Picea abies (L.) H. Karst.) when growing in mixture. They also found species specific tree crown adaptions: in mixtures beech had flatter branch angles, whereas spruce showed longer branches. Metz et al. (2013) showed that neighbourhood diversity significantly influenced beech growth and that intraspecific competition from beech is stronger than interspecific competition from other, more translucent species. These patterns were more pronounced when crown dimensions and shapes were derived from TLS data compared to the use of conventional geometric crown shapes. Moreover, Juchheim et al. (2017) detected that beech trees in mixtures were associated with longer branches with flatter angles, a lower height-to-diameter ratio and a lower height of the maximal lateral crown extension. Correspondingly, Barbeito et al. (2017) showed that beech trees in mixed stands with Scots pine (Pinus sylvestris L.) had larger crowns, especially in the lower canopy. However, the site productivity had a strong impact on this mixing effect. In a biodiversity-ecosystem functioning (BEF) experiment with young subtropical trees in China, Kunz et al. (2019) observed significant diversity effects on the crown architecture along a broad gradient of local neighbourhood species richness.

To fill the knowledge gap for mature European forests we extended previous studies by analysing further deciduous tree species that might play an important role (besides beech we also included Common oak (Quercus robur L.), Common hornbeam (Carpinus betulus L.), sycamore (Acer pseudoplatanus L.), Common ash (Fraxinus excelsior L.) and European larch (Larix decidua Mill.) and considered a longer tree species richness gradient of up to four in the local neighbourhood. Furthermore, most of the previous studies incorporated a relatively low number of target trees (mainly because traditional crown measurements in mature forest are highly time-consuming and modern high-resolution inventory tools such as TLS are analytically demanding). In this study we extended substantially the number of trees analysed to obtain more valid results. For analysing effects occurring on the local tree-to-tree scale it is of great advantage when the spatial resolution of the analysis is very high. Airborne laser scanning (ALS) and TLS have been successfully applied to capture crown characteristics (for an overview see Vosselman and Maas 2010). The earlier generations of laser scanners, however, mostly lack a high-resolution acquisition of the complex tree crowns in dense mature forests. In this study we make use of state-of-the-art technology of fullwaveform TLS with online waveform processing to measure a large number of individual trees in a highly accurate manner (Bienert et al. 2018; Georgi et al. 2018).

Of particular importance in examining a tree's local neighbourhood interactions is the identification of 
potential competitors and facilitators and hence, the relevant scale the local neighbourhood interactions in situ. Different distance-dependent approaches exist for neighbour inclusion (Biging and Dobbertin 1992; Rivas et al. 2005). In contrast to tree plantations and experiments, the stem and size distribution in natural forests is much more heterogeneous, resulting in potentially large differences when using different neighbour inclusion approaches (Rivas et al. 2005). Hence, Metz et al. (2013) points out the importance of unstandardized approaches to consider the crown size variation among equally thick and tall trees.

Given the technical progress of surveying instruments, the options for more precise and accurate neighbour inclusion approaches are improving. In the past this progress led to a selection by overlapping tree crowns with the help of crown mirrors instead of being confined to the use of circular plots with fixed radii around a target tree. Using this approach, von Oheimb et al. (2011) found no significant impact of neighbourhood diversity on tree growth. However, they only used the average crown radius of the horizontal projection of each tree, disregarding the actual overlap. In this study, we proceed a step further by using full-waveform TLS to detect every single branch with full extend and with the precise location in three-dimensional space to identify potentially interacting neighbours.

The aim of this study is to address two questions:

(1) How does local neighbourhood tree species diversity influence the tree morphology in mature European forests?

(2) How does local neighbourhood tree species diversity impact individual-tree productivity?

\section{Methods}

\section{Study area}

This study was performed in the Lauerholz Forest, located in south-eastern Schleswig-Holstein, Northern Germany, at a mean altitude of $20 \mathrm{~m}$ above sea level $\left(53^{\circ} 88^{\prime} \mathrm{N}\right.$, $10^{\circ} 74^{\prime}$ E). The study area is dominated by mixed-species deciduous forest, with a large number of different tree species (in particular F. sylvatica, Q. robur, C. betulus, $F$. excelsior, A. pseudoplatanus, Acer platanoides L., Prunus avium L., Betula pendula Roth, L. decidua). With a mean annual temperature of $8.3{ }^{\circ} \mathrm{C}$ and an annual precipitation of about $800 \mathrm{~mm}$, the study area is characterised by a suboceanic climate (Deutscher Wetterdienst 2017). The dominant soil texture is till with the associated soil types luvisols and pseudogleyic luvisols. The geological substrate originates from the last (Weichselian) glaciation.

\section{TLS data acquisition and registration}

For some of the analyses the growth data of the last decades were required (see below). Therefore, we investigated trees growing inside permanent circular inventory plots, each with a size of $500 \mathrm{~m}^{2}$ (radius $=12.62$ $\mathrm{m})$. These plots were established in 1992, and inventory data were recorded in 1992, 2003 and 2013. Based on the inventory data of 2013, 11 plots with two or more tree species and a minimum age of 60 years were selected. In order to capture all possible neighbouring trees for the analysis, all trees in a circular plot area of $1600 \mathrm{~m}^{2}$ (radius $=22.62 \mathrm{~m}$ ) were sampled. Additionally, for exceptionally large individuals growing near the plot boundary, we manually selected also even more remote neighbours in order to meet the requirements of the neighbour inclusion approach based on realised crown overlap (see below).

TLS data were recorded in March 2017, using a RIEGL VZ-400i full-waveform terrestrial laser scanner (RIEGL Laser Measurement Systems GmbH, Horn, Austria). Each plot was scanned in a multiple scan mode from five scanner positions (Liang et al. 2016), with one scanning position in the centre of the plot and the other four distributed in the cardinal directions at a distance of 23 to $25 \mathrm{~m}$ from the centre (slightly variable distances were used to select positions that most effectively reduced occlusions). The angular resolution was $0.04 \mathrm{deg}$ (corresponding to a resolution of $7 \mathrm{~mm}$ at $10 \mathrm{~m}$ ). At the centre positions, the scanner was also tilted by $90^{\circ}$ to overcome the limitation of the panoramic field of view. The instrument was mounted on a tripod and operated at a height of $1.30 \mathrm{~m}$. All scans were performed under clear skies and nearly windless conditions.

TLS point clouds were co-registered using the registration tools "Automatic Registration 2" and "Multi Station Adjustment" of Riegl RiSCAN Pro 2.6.1, resultant in a registration accuracy between 2.2 and $2.7 \mathrm{~mm}$ (Fig. 1a). To achieve a higher quality point cloud, stray and noise points with a so-called surface reflectance less than -25 $\mathrm{dB}$ or a pulse shape deviation greater than 15 , both terms defined by the scanner manufacturer Riegl, were removed (Pfennigbauer and Ullrich 2010). The reflectance value in $d B$ ranges from -25 up to 5 . The project coordinate system was defined by the plot centre point cloud and the other scanning positions were registered to this point cloud.

\section{TLS data post-processing}

All trees of the 11 plots with a diameter at breast height $(\mathrm{DBH}) \geq 7 \mathrm{~cm} \quad(n=920)$ were segmented in a stepwise procedure. First, the TLS point clouds were automatically segmented in trees with the SimpleTree (4.33.06) software, a plugin of Computree (5.0.054b) (Hackenberg et al. 2015). Second, the automatically extracted trees were visually checked, and falsely classified tree segments were manually corrected using RiSCAN PRO 


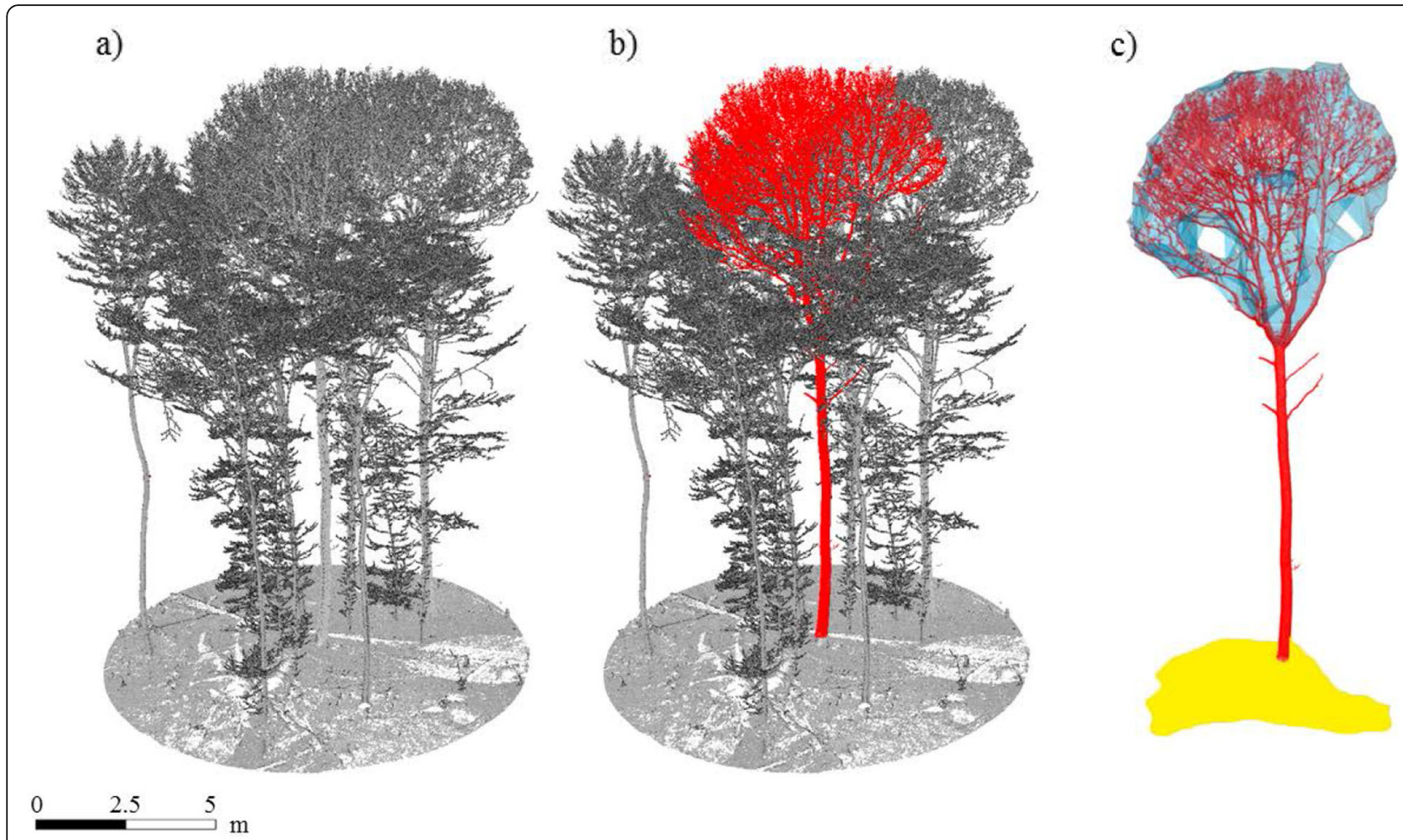

Fig. 1 a) Registered point cloud with multiple trees and ground; b) single segmented tree in red; c) crown volume in blue and crown projection area in yellow

Table 1 Morphologic traits measured for each sample tree

\begin{tabular}{|c|c|c|c|}
\hline Measure & Abbreviation & Origin & Reference/Calculation \\
\hline Basal area $\left(\mathrm{cm}^{2}\right)$ & $\mathrm{BA}$ & Point cloud/Inventory & $\mathrm{DBH}^{2} \times \pi / 4$ \\
\hline Diameter at breast height (cm) & $\mathrm{DBH}$ & QSM & Raumonen et al. (2013) \\
\hline Crown volume $\left(\mathrm{m}^{3}\right)$ & CV & Point cloud & See methods this publication \\
\hline Tree height (m) & $\mathrm{TH}$ & Point cloud & $Z_{\max }-Z_{\min }$ \\
\hline Total wood volume $\left(\mathrm{m}^{3}\right)$ & $V_{\text {tot }}$ & QSM & Raumonen et al. (2013) \\
\hline Merchantable wood volume $\left(\mathrm{m}^{3}\right)$ & $V_{\mathrm{mw}}$ & QSM & See methods this publication \\
\hline Volume of fine woody material $\left(\mathrm{m}^{3}\right)$ & $V_{\text {fwm }}$ & QSM & See methods this publication \\
\hline Crown base height (m) & $\mathrm{CBH}$ & Point cloud & See methods this publication \\
\hline Crown projection area $\left(\mathrm{m}^{2}\right)$ & CPA & Point cloud & See methods this publication \\
\hline Crown surface area $\left(\mathrm{m}^{2}\right)$ & CSA & Point cloud & See methods this publication \\
\hline Basal area increment $\left(\mathrm{cm}^{2} \cdot\right.$ year $\left.{ }^{-1}\right)$ & BAI & Point cloud/Inventory & $\triangle \mathrm{BA} / \Delta$ years \\
\hline Branch length sum (m) & & QSM & Raumonen et al. (2013) \\
\hline Mean branch angle 1st order $\left(^{\circ}\right)$ & & QSM & See methods this publication \\
\hline Mean branch angle 2nd order $\left(^{\circ}\right)$ & & QSM & See methods this publication \\
\hline Formula wood volume $\left(\mathrm{m}^{3}\right)$ & $V_{f}$ & Inventory & Bergel $(1973,1974)$ \\
\hline Formula wood volume increment $\left(\mathrm{m}^{3} \cdot \mathrm{year}^{-1}\right)$ & $V_{f} l$ & Inventory & $\Delta \mathrm{V}_{\mathrm{f}} \mathrm{l} / \Delta$ years \\
\hline
\end{tabular}


(Fig. 1b). The original point density was not reduced during the whole procedure to get the most accurate results.

Several tree characteristics (Table 1) and the aboveground wood volumes were derived for each segmented tree individual using quantitative structure models (QSMs). QSMs are a state-of-the-art approach (Raumonen et al. 2013) to quantify the 3D structure of a tree and its branching topology. QSMs deliver estimates of the aboveground wood volume with a high accuracy (Calders et al. 2015; Bienert et al. 2018). These models are a description of the tree as a hierarchical collection of geometric primitives (here: cylinders). They are embedded into the point cloud from which geometric and topological tree characteristics can be derived. To create the QSMs, we applied the TREEQSM (2.30) software developed by Raumonen et al. (2013), which runs within Matlab (MathWorks, Natick, MA, USA) version R2018b on the Taurus high-performance cluster (HPC) of the TU Dresden. The method categorizes the point cloud in the stem and single branches and captures the tree's topology. Afterwards a volume model is compiled by fitting cylinders in the point cloud segments (Raumonen et al. 2015; Kunz et al. 2017). Due to the parameter sensitivity of the modelling process, we conducted a parameter optimisation test with a subset of trees. This led to the following parameter values: first minimum patch size: $5 \mathrm{~cm}$; second minimum patch size: $1 \mathrm{~cm}$; second maximum patch size: $2 \mathrm{~cm}$; relative cylinder length: $4 \mathrm{~cm}$; relative radius for outlier removal: $5 \mathrm{~cm}$.

We extracted the basal area (BA), tree height (TH), total wood volume $\left(V_{\text {tot }}\right)$ and branch length of the TREE QSM output. We also computed the merchantable wood volume $\left(V_{\mathrm{mw}}\right)$, defined as all aboveground woody structures with a diameter $>7 \mathrm{~cm}$ (i.e. the trunk and the larger branches). The volume of fine woody material ( $V_{\text {fwm }}$; diameter $<7 \mathrm{~cm}$ ) was calculated as the difference of $V_{\text {tot }}$ and $V_{\mathrm{mw}}$

The trees mean branch angle was derived from all single branches and was calculated with the same method for the first- and second-order branches, respectively. To measure the branch's vertical orientation in space, we focused on the branch's exit angle by considering the first ten cylinders after the branch base, derived from the QSM. From those, the angle between the $\mathrm{Z}$-axes of the coordinate system and the mean branch axes was computed.

Moreover, we extracted numerous crown morphological traits. The crown base height $(\mathrm{CBH})$, defined as the height of the lowest living branch, was measured in RiSCAN Pro. The crown projection area (CPA), CV and crown surface area (CSA) for each tree were calculated with a concave hull (alpha-shape with $\alpha$-value $=0.3$ ) using the Point Cloud Library (Rusu and Cousins 2011) and the Computational Geometry Algorithms Library (Kai et al. 2019) (Fig. 1c).

\section{Target and neighbour tree selection}

The primary aim of this study was to analyse the neighbourhood diversity effect on an individual-tree level. In addition to the selection of the affected trees (in the following "target tree"), the determination of influencing neighbours is of central importance.

To focus on vigorous trees as target trees, we included only trees taller than two-thirds of the highest tree growing in the plot for all analyses. Tree species with rare occurrence $(N \leq 2)$ were excluded as target trees and one tree which was the only one having five neighbour tree species. A total of 920 trees was extracted from the TLS point clouds of which 148 were dedicated as target trees (61\% F. sylvatica, 20\% Q. robur, $12 \%$ C. betulus, 3\% F. excelsior, 2\% A. pseudoplatanus and 2\% L. decidua). For 47 target trees a full set of DBH measurements from the past three inventories was available.

Two approaches to identify the local neighbours were used. The first approach was a fixed radial distance of $10 \mathrm{~m}$ from the target tree. Parameters which have been calculated with these trees are subscripted with "radius". In the second approach, we used the highly accurate point cloud to classify all trees as neighbours which crowns were overlapping with that of the target tree (with alpha-shape; $\alpha$-value $=1$ ). Examples for the different outcomes resulting from the two neighbour selection approaches are shown in Fig. 2.

A total of 238 trees were determined as neighbouronly trees $(63 \%$ F. sylvatica, $17 \%$ Q. robur, $15 \%$ C. betulus, $3 \%$ F. excelsior, $1 \%$ P. avium and $1 \%$ L. decidua).

\section{Data analysis}

We applied two different approaches to quantify tree diversity in the local neighbourhood of a target tree (Table 2). The number of tree species (neighbourhood species richness, NSR) and the exponential Shannon index $\left(\mathrm{eH}_{\mathrm{S}}\right)$ based on the abundance of neighbouring trees (Shannon 1948; Jost 2006). $B_{i}$ is the sum of BA of all neighbouring trees of a given species $i$ and $B$ is the BA of all neighbours. Based on BA, this index has been used in former studies to describe forest diversity (Liang et al. 2007; Ratcliffe et al. 2015).

$$
\mathrm{eH}_{\mathrm{s}}=\exp \left(-\sum_{i=1}^{n_{\mathrm{S}}} \frac{B_{i}}{B} \ln \left(\frac{B_{i}}{B}\right)\right)
$$

The partitioning of canopy space was analysed using the crown complementarity index (CCI) according to 


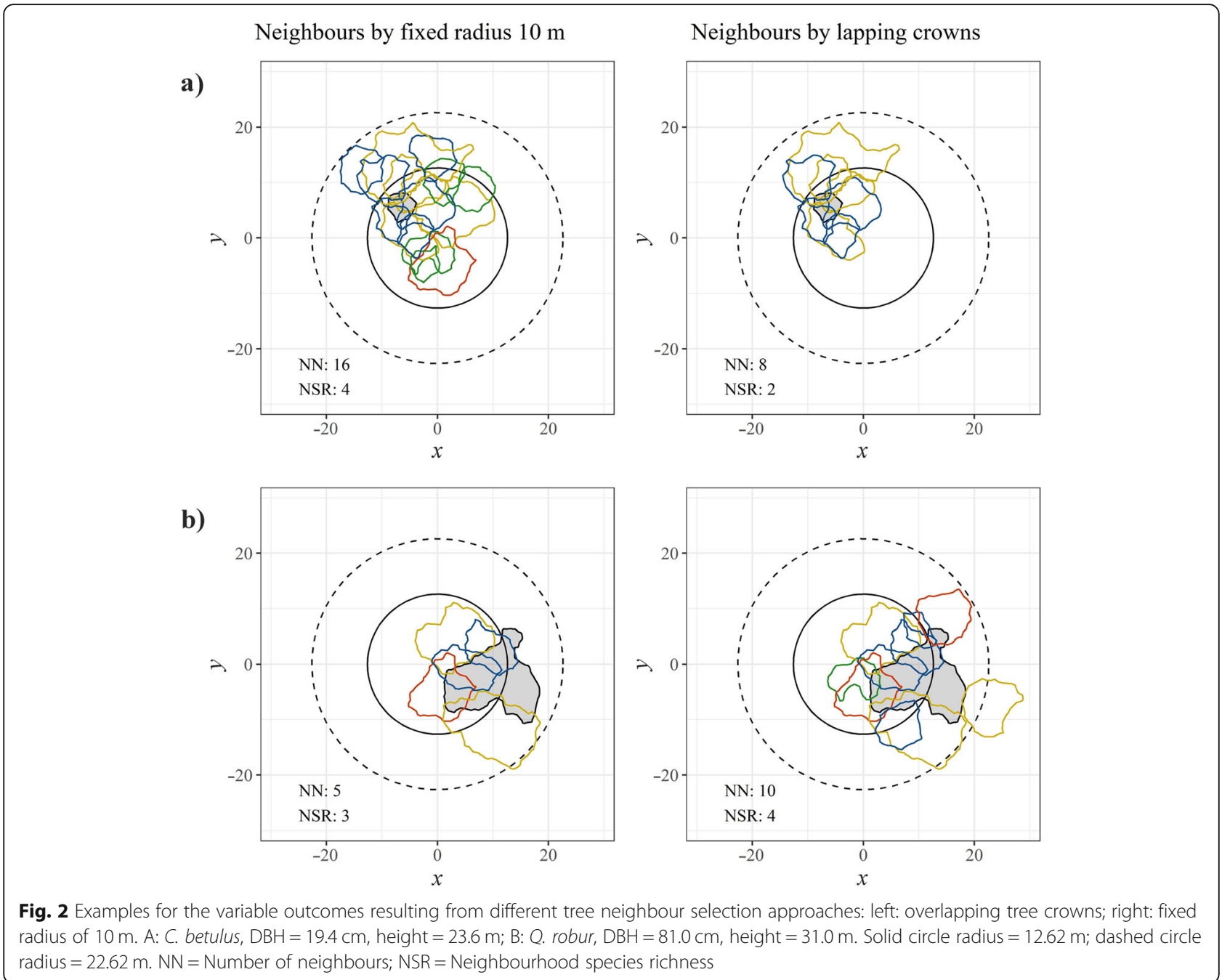

(Williams et al. 2017). Crown complementarity (CC) was calculated for two trees as the difference in crown volume $(V)$ between the two individuals $(i$ and $j)$ in each stratum $(k)$ summed across all strata. The CCI of a tree is the mean of all its neighbour CCs. We calculated the CCI with a strata height of $0.5 \mathrm{~m}$.

$$
\begin{aligned}
\mathrm{CC}_{i j} & =\frac{\sum\left|V_{i k}-V_{j k}\right|}{V_{i}-V_{j}} \\
\mathrm{CCI} & =\frac{\sum \mathrm{CC}_{i j}}{n}
\end{aligned}
$$

Basal area increment (BAI, $\mathrm{cm}^{2} \cdot \mathrm{year}^{-1}$ ) and the merchantable formula wood volume increment $\left(\mathrm{V}_{\mathrm{f}} \mathrm{I}\right.$, $\mathrm{m}^{3} \cdot$ year $^{-1}$ ) was calculated using DBH (by caliper) and height measurements (with vertex) from inventories in 1992 and 2013. Calculations for merchantable wood volume were based on volume functions by Bergel (1973; F. sylvatica, C. betulus, L. decidua) and Bergel (1974; Q. robur, F. excelsior, A. platanoides).

We applied linear mixed-effects models to assess the effects of tree diversity and space occupation on growth of target trees at the local neighbourhood scale. Explanatory variables were NSR, $\mathrm{eH}_{\mathrm{S}}$ or $\mathrm{CCI}$ (either based on the fixed radius or crown overlap neighbour selection approach) and the current $\mathrm{BA}$ or, for the increment models, the $\mathrm{BA}_{\text {init }}$. Target tree species identity and study plot were used as crossed random effects. The following response variables were used: CV, CPA, CSA, branch length sum, mean first order branch angel, mean second order branch angel, $V_{\text {tot }}$, $V_{\text {mw }}, V_{\text {fwm }}$, BAI and $\mathrm{V}_{\mathrm{f}}$ I. To improve the linear model fit and reduce the residual variance, we log-transformed the response variables and the BA. The model assumptions were tested and validated according to Zuur et al. (2009). Due to co-linearity of the competition (according to Hegyi 1974; Martin and Ak 1984; Biging and Dobbertin 1992) with the BA, we excluded these from the models. 
Table 2 Biodiversity and space partitioning indices measured for each target tree

\begin{tabular}{llll}
\hline Measure & Abbreviation & Origin & Reference/Calculation \\
\hline Neighbour species richness & $\mathrm{NSR}$ & Inventory & See methods this publication \\
Exponential Shannon-Index & $\mathrm{eH}_{\mathrm{S}}$ & Point cloud/Inventory & Shannon (1948) \\
Crown complementarity index & $\mathrm{CCl}$ & Point cloud & Williams et al. (2017) \\
\hline
\end{tabular}

All statistical data analysis was performed with $\mathrm{R}$ (3.6.1; R Core Team 2019) using the packages nlme (Pinheiro et al. 2019), lmerTest (Kuznetsova et al. 2019), MuMIn (Bartoń 2019) and effects (Fox et al. 2019).

\section{Results}

\section{Neighbourhood definition effect}

The two neighbour selection approaches yielded highly variable results regarding the number of neighbours $(\mathrm{NN})$ and NSR: the median $\triangle \mathrm{NN}$ was 3 , spanning a range from $\min =0$ to $\max =18$ and the median $\triangle \mathrm{NSR}$ was 0 , with a range of $\min =0$ and $\max =2$. An important factor to explain the differences between the two approaches is the tree dimension, especially the CPA. For trees with relatively small crowns, the $\mathrm{NN}$ is considerably higher using the fixed radius compared to the crown overlap approach. In contrast, an opposite pattern was found for the NN of large-crowned trees (see example in Fig. 2).

\section{Neighbourhood diversity effects on crown architecture and wood volume}

Besides the strong positive effect of the BA, NSR and $\mathrm{eH}_{\mathrm{S}}$ significantly positively influenced the tree crown dimensions (CV, CPA, CSA), branch length sum and the wood volumes based on the neighbour selection approach "crown overlap" (Table 3 and Fig. 3). In contrast, no significant influence of NSR and $\mathrm{eH}_{\mathrm{S}}$ on the response variables was found when using the fixed radius selection approach (with the only exception of a positive NSR effect on CV, Table 2). With both selection approaches, no impact of the diversity measures on the mean first or second order branch angel was observed. Moreover, the

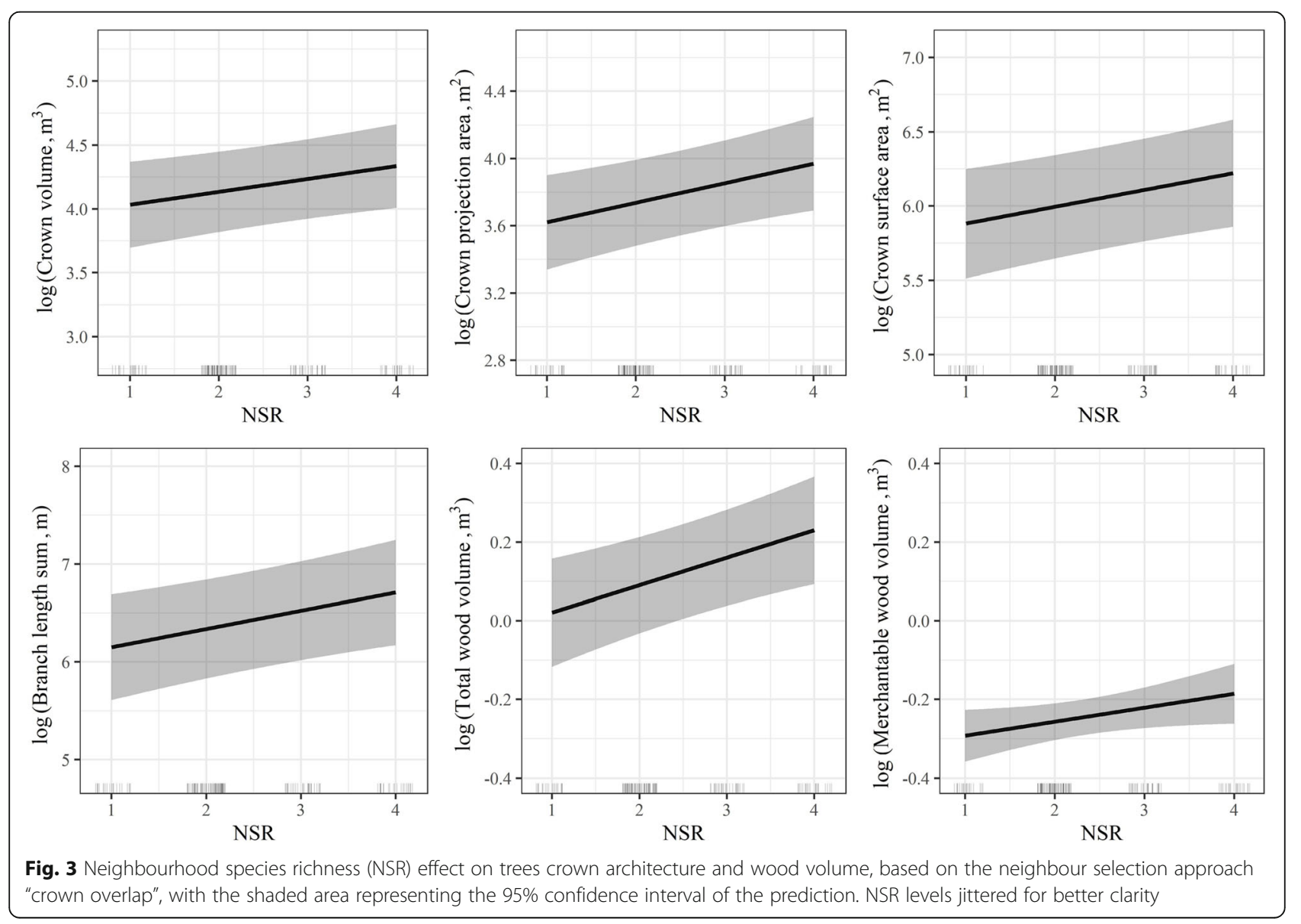


Table 3 Results of mixed-effects models for the effects of neighbourhood tree species richness (NSR), exponential Shannon index $\left(\mathrm{eH}_{\mathrm{s}}\right)$, crown complementarity index $(\mathrm{CCl})$ and target tree basal area (BA log $)$ on crown dimensions, branch length and wood volume based on the two tree neighbour selection approaches fixed radius and "overlapping crowns" (n target trees $=148$ ). In all models $\mathrm{BA}_{\text {log }} p=.: p<0.1$; $^{*}: p<0.05 ;{ }^{* *}: p<0.01$; $^{* *}: p<0.001 ;$ n.s. = not significant

\begin{tabular}{|c|c|c|c|c|c|c|c|}
\hline \multirow[t]{2}{*}{ Response variable } & \multirow{2}{*}{$\begin{array}{l}\text { Fixed } \\
\text { effects }\end{array}$} & \multicolumn{3}{|l|}{ Fixed radius } & \multicolumn{3}{|c|}{ Overlapping crowns } \\
\hline & & Estimates & $p$ & $R_{c}^{2}$ & Estimates & $p$ & $R_{c}^{2}$ \\
\hline \multirow[t]{3}{*}{ Crown volume (log) } & $\mathrm{NSR}+\mathrm{BA}_{\log }$ & $0.08+0.98$ & * & 0.89 & $0.09+0.95$ & * & 0.89 \\
\hline & $\mathrm{eH}_{\mathrm{S}}+\mathrm{BA}_{\log }$ & $0.01+0.95$ & n.s. & 0.89 & $0.08+0.96$ & * & 0.89 \\
\hline & $\mathrm{CCl}+\mathrm{BA}_{\log }$ & $0.04+0.95$ & n.s. & 0.89 & $-0.10+0.93$ & ** & 0.89 \\
\hline \multirow[t]{3}{*}{ Crown projection area (log) } & $N S R+B A_{\log }$ & $0.04+0.70$ & n.s. & 0.85 & $0.10+0.70$ & ** & 0.86 \\
\hline & $\mathrm{eH}_{\mathrm{S}}+\mathrm{BA}_{\log }$ & $-0.01+0.69$ & n.s. & 0.85 & $0.08+0.71$ & * & 0.86 \\
\hline & $\mathrm{CCl}+\mathrm{BA}_{\log }$ & $0.04+0.69$ & n.s. & 0.85 & $-0.02+0.69$ & n.s. & 0.84 \\
\hline \multirow[t]{3}{*}{ Crown surface area (log) } & $N S R+B A_{\log }$ & $0.06+0.93$ & n.s. & 0.89 & $0.10+0.92$ & $* *$ & 0.90 \\
\hline & $\mathrm{eH}_{\mathrm{S}}+\mathrm{BA}_{\log }$ & $0.00+0.91$ & n.s. & 0.89 & $0.08+0.93$ & $*$ & 0.90 \\
\hline & $\mathrm{CCl}+\mathrm{BA}_{\log }$ & $0.01+0.91$ & n.s. & 0.89 & $-0.05+0.89$ & n.s. & 0.89 \\
\hline \multirow[t]{3}{*}{ Branch length sum (log) } & $\mathrm{NSR}+\mathrm{BA}_{\log }$ & $0.09+0.70$ & n.s. & 0.76 & $0.17+0.68$ & ** & 0.77 \\
\hline & $\mathrm{eH}_{\mathrm{S}}+\mathrm{BA}_{\log }$ & $0.00+0.68$ & n.s. & 0.75 & $0.13+0.69$ & * & 0.77 \\
\hline & $\mathrm{CCl}+\mathrm{BA}_{\log }$ & $0.01+0.68$ & n.s. & 0.76 & $-0.07+0.67$ & n.s. & 0.74 \\
\hline \multirow[t]{3}{*}{ Total wood volume (log) } & $\mathrm{NSR}+\mathrm{BA}_{\log }$ & $0.02+0.96$ & n.s. & 0.97 & $0.06+0.96$ & $* *$ & 0.97 \\
\hline & $\mathrm{eH}_{\mathrm{S}}+\mathrm{BA}_{\log }$ & $0.00+0.96$ & n.s. & 0.97 & $0.05+0.96$ & ** & 0.97 \\
\hline & $\mathrm{CCl}+\mathrm{BA}_{\log }$ & $-0.03+0.96$ & n.s. & 0.97 & $-0.05+0.95$ & $* * *$ & 0.97 \\
\hline \multirow[t]{3}{*}{ Fine woody material volume (log) } & $\mathrm{NSR}+\mathrm{BA}_{\log }$ & $0.06+0.70$ & n.s. & 0.81 & $0.14+0.69$ & ** & 0.82 \\
\hline & $\mathrm{eH}_{\mathrm{S}}+\mathrm{BA}_{\mathrm{log}}$ & $-0.01+0.69$ & n.s. & 0.81 & $0.12+0.70$ & ** & 0.82 \\
\hline & $\mathrm{CCl}+\mathrm{BA}_{\log }$ & $-0.01+0.70$ & n.s. & 0.81 & $-0.07+0.67$ & ** & 0.80 \\
\hline \multirow[t]{3}{*}{ Merchantable wood volume (log) } & $\mathrm{NSR}+\mathrm{BA}_{\log }$ & $0.01+1.07$ & n.s. & 0.98 & $0.03+1.06$ & . & 0.98 \\
\hline & $\mathrm{eH}_{\mathrm{S}}+\mathrm{BA}_{\mathrm{log}}$ & $0.02+1.07$ & n.s. & 0.98 & $0.03+1.06$ & . & 0.98 \\
\hline & $\mathrm{CCl}+\mathrm{BA}_{\mathrm{log}}$ & $-0.04+1.08$ & $* *$ & 0.98 & $-0.04+1.07$ & $* *$ & 0.98 \\
\hline
\end{tabular}

$\mathrm{CV}$ and the wood volumes significantly increased with lower CCI.

\section{Neighbourhood diversity effects on individual-tree productivity}

The effects of NSR on tree productivity (BAI and $\mathrm{V}_{\mathrm{f}} \mathrm{I}$ ) strongly depended on the initial size (i.e. BA) of a target tree. For small-sized trees, BAI was higher in conspecific than in heterospecific neighbourhoods, while large-sized trees benefitted from increasing NSR (Table 4 and Fig. 4). Interacting with the $\mathrm{BA}_{\text {init.log, }}$ NSR and $\mathrm{eH}_{\mathrm{S}}$ had significant positive impacts on both, BAI and $\mathrm{V}_{\mathrm{f}} \mathrm{I}$, over the past 21 years. The local $\mathrm{CCI}$ interacting with the $\mathrm{BA}_{\text {init.log }}$ also showed a tendency towards a positive influence on tree growth. Again, there is a high sensitivity of the results towards the neighbour selection approach, because most the investigated effects solely occurred or were stronger with the neighbour selection approach "crown overlap" than with "fixed radius" definition (data not shown).

\section{Discussion}

In the mature mixed-species forests examined in this study we observed significant impact of the local neighbourhood tree diversity on crown architecture as well as on wood volume and growth. These findings were, however, very sensitive to the approach used to select neighbouring trees. Whereas the fixed radial distance approach barely yielded significant results, this was always the case using the neighbour selection based on overlapping crowns. Mature forests composed of late successional tree species display a wide range of tree sizes at small spatial scales. The large differences in the performance of the two approaches points to an important role of aboveground interactions, i.e. competition for physical space and light. Previous studies used various different approaches to calculate a tree's zone of influence or its competitors (Bachmann 1998). Earlier methods to determine the exact crown dimensions and neighbours of a tree using a compass, hypsometer and crown mirror are error-prone and time-consuming. Hence, an often-used simple neighbour selection is 
Table 4 Results of mixed-effects models for effects of target tree initial basal area ( $\left.\mathrm{BA}_{\text {init }}\right)$, neighbourhood tree species richness (NSR), exponential Shannon index $\left(\mathrm{eH}_{\mathrm{S}}\right)$ and crown complementarity index $(\mathrm{CCl})$ on basal area increment and wood volume increment with the neighbour selection approach "crown overlap" $(n=47) . .: p<0.1$; *: $p<0.05$; **: $p<0.01$

\begin{tabular}{|c|c|c|c|c|c|c|}
\hline \multirow[t]{2}{*}{ Fixed effects } & \multicolumn{3}{|c|}{ Basal area increment (log) } & \multicolumn{3}{|c|}{ Volume formula increment (log) } \\
\hline & Estimate & $p$ & $R_{C}^{2}$ & Estimate & $p$ & $R_{C}^{2}$ \\
\hline$N S R \times B A_{\text {init.log }}$ & 0.161 & . & 0.79 & 0.186 & * & 0.82 \\
\hline $\mathrm{eH}_{\mathrm{S}} \times \mathrm{BA}_{\text {init.log }}$ & 0.177 & * & 0.80 & 0.205 & ** & 0.83 \\
\hline $\mathrm{CCl} \times \mathrm{BA}_{\text {init.log }}$ & 0.116 & . & 0.76 & 0.110 & . & 0.78 \\
\hline
\end{tabular}

the use of fixed radii, a worldwide uniform approach which is also cost effective without the use of TLS. This method, however, has two disadvantages. First, it only considers the fixed stem base location. This is the position where the seed sprouted and the tree individual has been able to prevail until today. However, the competition for light, water and nutrients at this spot changes in the course of decades. In our study area, water and nutrient supply are generally not limiting tree growth. Rather, trees compete for light (Schwinning and Weiner 1998) and competition effects occur on the crown distribution (Longuetaud et al. 2013). Therefore, it is reasonable to select neighbours based on the photosynthetically active part of a tree, the crown. The actual shape of a crown represents the accumulated competitive circumstances of the past. A second disadvantage of a fixed-radius approach is the neglection of tree size differences by using the same radius for a range of different sizes. It has often been found that the optimal radial distances strongly depended on tree size dimensions (D'Amato and Puettmann 2004). In heterogeneous forests the choice of one specific radius will always remain a compromise. In our study, the minimum and maximum crown diameters were 3.48 and $17.00 \mathrm{~m}$ or 4.59 and $23.45 \mathrm{~m}$, derived from the CPA and from the maximal chord, respectively. As an alternative to a single fixed radius, several studies used either a variety of radii (Lin and Augspurger 2006; Antos et al. 2010; Ratcliffe et al. 2015) or tree size dependent radii (von Oheimb et al. 2011). However, the strong advantage of the crown overlap approach is to focus on every individual tree and its actual surrounding structure in three dimensions (Zambrano et al. 2019). At this level of resolution, the procedure is only possible due to the application of highly precise TLS for forest science and ecology. Deploying this state-of-the-art technology enables enhanced insights in the outcome of tree-tree interactions at the local scale, even in temperate mature forests with canopy heights of up to $45 \mathrm{~m}$.

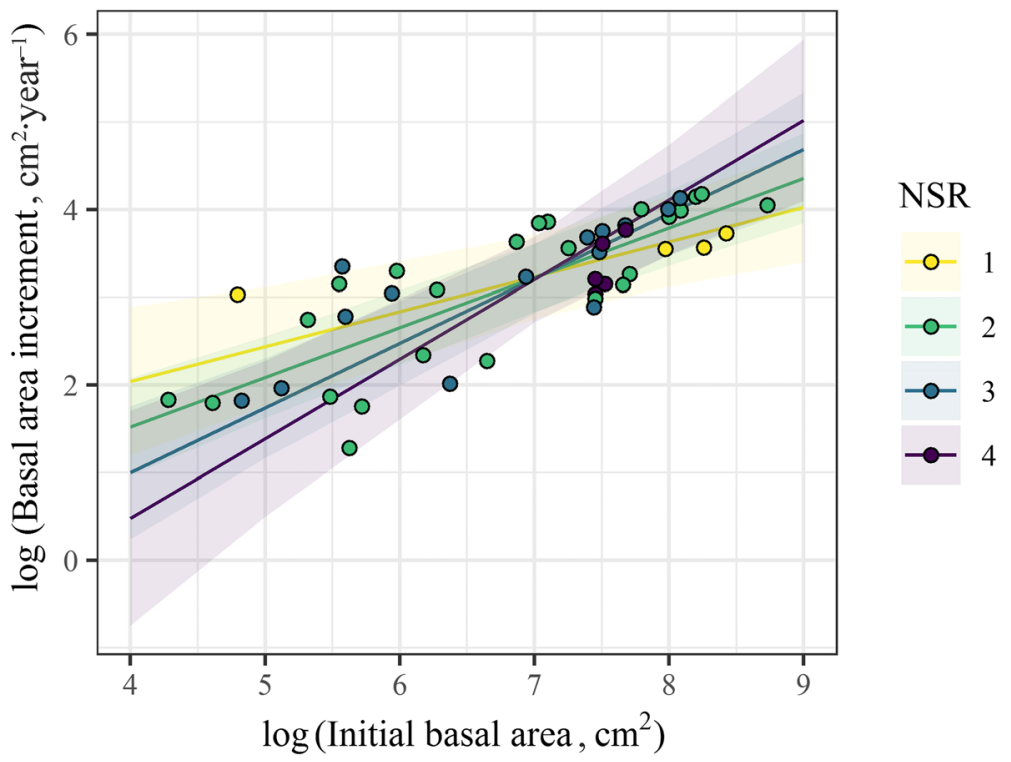

Fig. 4 Size-dependency of neighbourhood species richness (NSR) effects on the annual basal area increment with the neighbour selection approach "crown overlap", with the shaded area representing the 95\% confidence interval of the prediction 
Our results confirm previous findings that an increase in neighbourhood tree species richness allows trees to enhance their crowns in size and shape (Bayer et al. 2013; Kunz et al. 2019). The diversitydriven plasticity is gained by enhanced branch lengths and an increased biomass allocation to fine woody material $\left(V_{\mathrm{fwm}}\right)$, leading to larger $\mathrm{CPA}$ and greater CSA and thus to larger crown volume. Pretzsch (2014) stated, the more species, the larger the sum of the crown area. A tree's individual crown growth is a modular reaction to microenvironmental light heterogeneity (Kawamura 2010) and thus elementary in the compensatory feedback loop between structure, environment and growth (Bayer et al. 2013; Pretzsch 2014). Through the combination of species with different light ecology and crown morphology, the canopy is more diverse and the individual trees can respond and therefore utilize the canopy space in a more complementary way (Pretzsch 2014). Our results support the niche complementarity hypothesis, postulating the more efficient use of resources, here the physical partitioning in canopy space, by coexisting species (Tilman 1999; Forrester and Bauhus 2016). Along with higher architectural plasticity of individual trees the whole canopy might be packed denser (Cianciaruso et al. 2009).

With the enlargement of the crown and an increase in leaf-bearing branches of higher orders, there is an increase in photosynthetically active area. Under the significant impact of local neighbourhood diversity, the 47 observed trees in this study show an ambivalent growth pattern over 21 years. Smaller trees with a DBH smaller than $40 \mathrm{~cm}$ are impeded in their radial growth whereas larger trees benefitted from increasing NSR. These results are similar to those of Lasky et al. (2015) and Fichtner et al. (2017) who observed that taller tree individuals benefiting more from a diverse neighbourhood. This might be due to size-asymmetric competition (Schwinning and Weiner 1998) of larger trees receiving disproportionally more light in comparison to smaller individuals and thus the ability to occupy free niches earlier. Divers tree species mixtures could further enhance this effect.

In contrast to Williams et al. (2017) who studied young and comparatively small trees, we observed a negative effect of the CCI on $\mathrm{CV}$ and wood volume. However, a reverse reasoning is also plausible. The bigger the crowns, the more equal they are. Since we have studied mature trees, close to their maximum height, we suspect an upper growth limit and rather the $\mathrm{CBH}$ as a decisive influence on this parameter. Moreover, the averaging effect of the $\mathrm{CCI}$ is notable, neglecting a trees opportunity to shift crown growth to a less competing direction (Ali 2019).

Since different structural characteristics induce various reactions among species with different resource-use strategies, the mixing effect is species-specific (Fichtner et al. 2017; Forrester 2019). To analyse the speciesspecific neighbour effects in temperate European mixed forests with precise laser scanning technology might be the next step, requiring even more trees to achieve statistically solid results.

\section{Conclusions}

With our study, we provide evidence that neighbourhood species mixing has a significant influence on individual tree morphology and productivity in mature European mixed-species forest. Moreover, we showed the importance of a precise neighbourhood definition and selection procedure to reveal diversity effects in mature natural and near-natural stands.

For future studies in heterogeneous mixed forests, it would be advantageous to include an even larger number of trees to facilitate analyses across extensive areas. A possible approach to advance in this direction is the application of mobile laser scanning (Bienert et al. 2018) in combination with largely automated individual-tree segmentation procedures. This can be used to clarify two important questions. On the one hand, it enables the mixture effects to be examined for species-specific mixing effects. On the other hand, the diversity effect can be studied on several spatial scales with the help of a much larger dataset.

\section{Abbreviations}

ALS: Airborne laser scanning; BA: Basal area; BAl: Basal area increment; BEF: Biodiversity-ecosystem functioning; $\mathrm{CBH}$ : Crown base height; $\mathrm{CC}$ : Crown complementarity; CCl: Crown complementarity index; CPA: Crown projection area; CSA: Crown surface area; CV: Crown volume; DBH: Diameter at breast height; eHs: Exponential Shannon-Index; HPC: High-performance cluster; N: Number; NN: Number of neighbours; NSR: Neighbour species richness; QSM: Quantitative structure model; TH: Tree height; TLS: Terrestrial laser scanning; $V_{f}$ : Formula wood volume; $V_{f}$ : Formula wood volume increment; $V_{\text {fwm }}$ : Volume of fine woody material; $V_{\text {mw: }}$ : Merchantable wood volume; $V_{\text {tot }}$ :Total wood volume

\section{Acknowledgments}

We thank the Forestry Offices of the City of Lübeck County for permission to conduct this study in their forests. The QSM calculations were made on the Taurus HPC cluster of the ZIH of the TU Dresden. Moreover, we would like to thank the anonymous reviewers for their comments and suggestions on the manuscript.

\section{Authors' contributions}

LG and GvO conceptualized the study; KFR and GvO recorded the data; LG, MK, AF and KFR analysed the data; LG prepared the original draft and all authors reviewed and edited the manuscript. The author(s) read and approved the final manuscript

\section{Funding}

LG was funded by the German Research Foundation (DFG 320926971) through the project "Analysis of diversity effects on above-ground 
productivity in forests: advancing the mechanistic understanding of spatiotemporal dynamics in canopy space filling using mobile laser scanning".

\section{Availability of data and materials}

Data are available from the corresponding author on reasonable request.

\section{Declarations}

\section{Ethics approval and consent to participate}

The subject has no ethic risk

\section{Consent for publication}

Not applicable.

\section{Competing interests}

The authors declare no conflict of interest. The funders had no role in the design of the study; in the collection, analyses, or interpretation of data; in the writing of the manuscript, or in the decision to publish the results.

\section{Author details}

${ }^{1}$ Technische Universität Dresden, Institute of General Ecology and Environmental Protection, Pienner Straße 7, 01737 Tharandt, Germany. 2Leuphana University of Lüneburg, Institute of Ecology, Universitätsallee 1, 21335 Lüneburg, Germany. ${ }^{3}$ Technische Universität Dresden, Institute of Photogrammetry and Remote Sensing, Helmholtzstraße 10, 01069 Dresden, Germany.

\section{Received: 15 May 2020 Accepted: 13 November 2020}

Published online: 26 April 2021

\section{References}

Ali A (2019) Forest stand structure and functioning: current knowledge and future challenges. Ecol Indic 98:665-677. https://doi.org/10.1016/j.ecolind.201 8.11 .017

Antos JA, Parish R, Nigh GD (2010) Effects of neighbours on crown length of Abies lasiocarpa and Picea engelmannii in two old-growth stands in British Columbia. Can J For Res 40(4):638-647. https://doi.org/10.1139/X10-011

Bachmann M (1998) Indizes zur Erfassung der Kokurrenz von Einzelbäumen Methodische Untersuchung in Bergmischwäldern. Dissertation. Universität München, München

Barbeito I, Dassot M, Bayer D, Collet C, Drössler L, Löf M, del Rio M, Ruiz-Peinado R, Forrester DI, Bravo-Oviedo A, Pretzsch H (2017) Terrestrial laser scanning reveals differences in crown structure of Fagus sylvatica in mixed vs. pure European forests. For Ecol Manag 405:381-390. https://doi.org/10.1016/j. foreco.2017.09.043

Bartoń K (2019) MuMIn: Multi-Model Inference. R package version 1.43.6. https:// www.readkong.com/page/package-mumin-the-r-project-for-statisticalcomputing-2339074. Accessed 09 Sept 2019

Bastin J-F, Finegold Y, Garcia C, Mollicone D, Rezende M, Routh D, Zohner CM, Crowther TW (2019) The global tree restoration potential. Science 365(6463): 76-79. https://doi.org/10.1126/science.aay8060

Bayer D, Seifert S, Pretzsch H (2013) Structural crown properties of Norway spruce (Picea abies [L.] Karst.) and European beech (Fagus sylvatica [L.]) in mixed versus pure stands revealed by terrestrial laser scanning. Trees-Struct Funct 27(4):1035-1047. https://doi.org/10.1007/s00468-013-0854-4

Bergel D (1973) Formzahluntersuchungen an Buche, Fichte, europäischer Lärche und japanischer Lärche zur Aufstellung neuer Massentafeln. Allg Forst und Jagd Zeitschrift 144:117-124

Bergel D (1974) Massentafeln II Eiche Roteiche Kiefer. Niedersächsische Forstliche Versuchsanstalt, Göttingen

Bienert A, Georgi L, Kunz M, Maas HG, von Oheimb G (2018) Comparison and combination of mobile and terrestrial laser scanning for natural forest inventories. Forests 8(7):1-25. https://doi.org/10.3390/f9070395

Biging GS, Dobbertin M (1992) A comparison of distance-dependent competition measures for height and basal area growth of individual conifer trees. For Sci 38:695-720. https://doi.org/10.1093/forestscience/38.3.695

Calders K, Newnham G, Burt A, Murphy S, Raumonen P, Herold M, Culvenor D, Avitabile V, Disney M, Armston J, Kaasalainen M (2015) Nondestructive estimates of above-ground biomass using terrestrial laser scanning. Methods Ecol Evol 6(2):198-208. https://doi.org/10.1111/2041-210X.12301
Cianciaruso MV, Batalha MA, Gaston KJ, Petchey OL (2009) Including intraspecific variability in functional diversity. Ecology 90(1):81-89. https://doi.org/10.1890/ 07-1864.1

Costes E, Gion JM (2015) Genetics and genomics of tree architecture. In: Plomion C, Adam-Blondon A-F (eds) Advances in botanical research. Land Plants Trees. Elsevier, Amsterdam, pp 157-200

D'Amato AW, Puettmann KJ (2004) The relative dominance hypothesis explains interaction dynamics in mixed species Alnus rubra/Pseudotsuga menziesii stands. J Ecol 92(3):450-463. https://doi.org/10.1111/j.0022-0477.2004.00888.x

De Kroon H, Huber H, Stuefer JF, Van Groenendael JM (2005) A modular concept of phenotypic plasticity in plants. New Phytol 166(1):73-82. https://doi.org/1 0.1111/j.1469-8137.2004.01310.x

del Río M, Bravo-Oviedo A, Ruiz-Peinado R, Condés S (2019) Tree allometry variation in response to intra- and inter-specific competitions. Trees-Struct Funct 33(1):121-138. https://doi.org/10.1007/s00468-018-1763-3

Fichtner A, Härdtle W, Li Y, Bruelheide H, Kunz M, von Oheimb G (2017) From competition to facilitation: how tree species respond to neighbourhood diversity. Ecol Lett 20(7):892-900. https://doi.org/10.1111/ele.12786

Fichtner A, Sturm K, Rickert C, von Oheimb G, Härdtle W (2013) Crown sizegrowth relationships of European beech (Fagus sylvatica L.) are driven by the interplay of disturbance intensity and inter-specific competition. For Ecol Manag 302:178-184. https://doi.org/10.1016/j.foreco.2013.03.027

Forrester DI (2019) Linking forest growth with stand structure: tree size inequality, tree growth or resource partitioning and the asymmetry of competition. For Ecol Manag 447:139-157. https://doi.org/10.1016/j.foreco.2019.05.053

Forrester DI, Ammer C, Annighöfer PJ, Barbeito I, Bielak K, Bravo-Oviedo A, Coll L, del Río M, Drössler L, Heym M, Hurt V, Löf M, den Ouden J, Pach M, Pereira MG, Plaga BNE, Ponette Q, Skrzyszewski J, Sterba H, Svoboda M, Zlatanov TM, Pretzsch H (2018) Effects of crown architecture and stand structure on light absorption in mixed and monospecific Fagus sylvatica and Pinus sylvestris forests along a productivity and climate gradient through Europe. J Ecol 106(2):746-760. https://doi.org/10.1111/1365-2745.12803

Forrester DI, Bauhus J (2016) A review of processes behind diversity productivity relationships in forests. Curr For Rep 2(1):45-61. https://doi.org/1 0.1007/s40725-016-0031-2

Forrester DI, Benneter A, Bouriaud O, Bauhus J (2017) Diversity and competition influence tree allometric relationships - developing functions for mixed-species forests. J Ecol 105(3):761-774. https://doi.org/10.1111/1365-2745.12704

Fox J, Weisberg S, Price B, Friendly M, Hong J, Andersen R, Firth D, Taylor S (2019) Effects-package: effect displays for linear, generalized linear, and other models. R package version 4.1.1. https://www.r-project.org, http://socserv. socsci.mcmaster.ca/jfox/. Accessed 09 Sept 2020

Georgi L, Kunz M, Fichtner A, Härdtle W, Reich KF, Sturm K, Welle T, von Oheimb G (2018) Long-term abandonment of forest management has a strong impact on tree morphology and wood volume allocation pattern of European beech (Fagus sylvatica L.). Forests 9:704. https://doi.org/10.3390/ f9110704

Guillemot J, Kunz M, Schnabel F, Fichtner A, Madsen CP, Gebauer T, Härdtle W, von Oheimb G, Potvin C (2020) Neighbourhood-mediated shifts in tree biomass allocation drive overyielding in tropical species mixtures. New Phytol 228(4):1256-1268. https://doi.org/10.1111/nph.16722

Hackenberg J, Wassenberg M, Spiecker H, Sun D (2015) Non destructive method for biomass prediction combining TLS derived tree volume and wood density. Forests 6(12):1274-1300. https://doi.org/10.3390/f6041274

Hegyi F (1974) A simulation model for managing jack-pine stands. In: Fries J (ed) Groth Models for tree and stand simulation - International Union of Forestry Research Organisations Working Party s4.01-4 - Proceedings of Meetings in 1973. Royal College of Forestry, Stockholm, pp 74-90

Huang Y, Chen Y, Castro-Izaguirre N, Baruffol M, Brezzi M, Lang A, Li Y, Härdtle W, von Oheimb G, Yang X, Liu X, Pei K, Both S, Yang B, Eichenberg D, Assmann T, Bauhus J, Behrens T, Buscot F, Chen X-Y, Chesters D, Ding B-Y, Durka W, Erfmeier A, Fang J, Fischer M, Guo L-D, Guo D, Gutknecht JLM, He J-S, He CL, Hector A, Hönig L, Hu R-Y, Klein A-M, Kühn P, Liang Y, Li S, Michalski S, Scherer-Lorenzen M, Schmidt K, Scholten T, Schuldt A, Shi X, Tan M-Z, Tang Z, Trogisch S, Wang Z, Welk E, Wirth C, Wubet T, Xiang W, Yu M, Yu X-D, Zhang J, Zhang S, Zhang N, Zhou H-Z, Zhu C-D, Zhu L, Bruelheide H, Ma K, Niklaus PA, Schmid B (2018) Impacts of species richness on productivity in a large-scale subtropical forest experiment. Science 362:80-83. https://doi.org/1 $0.1126 /$ science.aat6405

Ishii H, Asano S (2010) The role of crown architecture, leaf phenology and photosynthetic activity in promoting complementary use of light among 
coexisting species in temperate forests. Ecol Res 25(4):715-722. https://doi. org/10.1007/s11284-009-0668-4

Jost L (2006) Entropy and diversity. Oikos 113(2):363-375. https://doi.org/10.1111/ j.2006.0030-1299.14714.x

Juchheim J, Annighöfer P, Ammer C, Calders K, Raumonen P, Seidel D (2017) How management intensity and neighborhood composition affect the structure of beech (Fagus sylvatica L.) trees. Trees-Struct Funct 31(5):17231735. https://doi.org/10.1007/s00468-017-1581-z

Kai T, Da F, Yvinec M (2019) 3D Alpha Shapes. https://doc.cgal.org/latest/Alpha_ shapes_3/index.html. Accessed 09 Sept 2019

Kawamura K (2010) A conceptual framework for the study of modular responses to local environmental heterogeneity within the plant crown and a review of related concepts. Ecol Res 25(4):733-744. https://doi. org/10.1007/s11284-009-0688-0

Kunz M, Fichtner A, Härdtle W, Raumonen P, Bruelheide H, von Oheimb G (2019) Neighbour species richness and local structural variability modulate aboveground allocation patterns and crown morphology of individual trees. Ecol Lett 22(12):2130-2140. https://doi.org/10.1111/ele.13400

Kunz M, Hess C, Raumonen P, Bienert A, Hackenberg J, Maas HG, Härdtle W, Fichtner A, von Oheimb G (2017) Comparison of wood volume estimates of young trees from terrestrial laser scan data. iForest 10:451-458. https://doi. org/10.3832/ifor2151-010

Kuznetsova A, Brockhoff PB, Christensen RHB (2019) ImerTest: tests in linear mixed effects models. $R$ package version 3.1.0

Lang AC, Härdtle W, Bruelheide H, Geißler C, Nadrowski K, Schuldt A, Yu M, von Oheimb G (2010) Tree morphology responds to neighbourhood competition and slope in species-rich forests of subtropical China. For Ecol Manag 260(10):1708-1715. https://doi.org/10.1016/j.foreco.2010.08.015

Lasky JR, Bachelot B, Muscarella R, Schwartz N, Forero-Montaña J, Nytch CJ, Swenson NG, Thompson J, Zimmermann JK, Uriarte M (2015) Ontogenetic shifts in trait-mediated mechanisms of plant community assembly. Ecology 96(8):2157-2169. https://doi.org/10.1890/14-1809.1

Li Y, Zhao M, Motesharrei S, Mu Q, Kalnay E, Li S (2015) Local cooling and warming effects of forests based on satellite observations. Nat Commun 6(1): 6603. https://doi.org/10.1038/ncomms7603

Liang J, Buongiorno J, Monserud RA, Kruger EL, Zhou M (2007) Effects of diversity of tree species and size on forest basal area growth, recruitment, and mortality. For Ecol Manag 243(1):116-127. https://doi.org/10.1016/j.foreco.2 007.02.028

Liang X, Kankare V, Hyyppä J, Wang Y, Kukko A, Haggrén H, Yu X, Kaartinen H, Jaakkola A, Guan F, Holopainen M, Vastaranta M (2016) Terrestrial laser scanning in forest inventories. ISPRS J Photogramm Remote Sens 115:63-77. https://doi.org/10.1016/j.isprsjprs.2016.01.006

Lin Y, Augspurger C (2006) A long-term study of neighbour-regulated demography during a decline in forest species diversity. J Veg Sci 17(1):93102. https://doi.org/10.1658/1100-9233(2006)017[0093:ALSOND]2.0.CO;2

Longuetaud F, Piboule A, Wernsdörfer H, Collet C (2013) Crown plasticity reduces inter-tree competition in a mixed broadleaved forest. Eur J For Res 132(4): 621-634. https://doi.org/10.1007/s10342-013-0699-9

Martin GL, Ak AR (1984) A comparison of competition measures and growth models for predicting plantation red pine diameter and height growth. For Sci 30:731-743. https://doi.org/10.1093/forestscience/30.3.731

Metz J, Seidel D, Schall P, Scheffer D, Schulze ED, Ammer C (2013) Crown modeling by terrestrial laser scanning as an approach to assess the effect of aboveground intra- and interspecific competition on tree growth. For Ecol Manag 310:275-288. https://doi.org/10.1016/j.foreco.2013.08.014

Morin X, Fahse L, Scherer-Lorenzen M, Bugmann H (2011) Tree species richness promotes productivity in temperate forests through strong complementarity between species. Ecol Lett 14(12):1211-1219. https://doi.org/10.1111/j.14610248.2011.01691.x

Ozanne CHP, Anhuf D, Boulter SL, Keller H, Kitching RL, Körner C, Meinzer FC, Mitchell AW, Nakashizuka T, Silva Dias PL, Stork NE, Wright SJ, Yoshimura M (2003) Biodiversity meets the atmosphere: a global view of forest canopies. Science 301(5630):183-186. https://doi.org/10.1126/science.1084507

Pfennigbauer M, Ullrich A (2010) Improving quality of laser scanning data acquisition through calibrated amplitude and pulse deviation measurement. In: Proceeding of SPIE 7684, laser radar technology and applications XV, $76841 \mathrm{~F}$, Orlando

Pinheiro J, Bates D, DebRoy S, Sarkar D, Heisterkamp S, Van Willigen B (2019) nlme: Linear and nonlinear mixed effects models. R package version 3.1.137.
https://rweb.webapps.cla.umn.edu/R/library/nlme/html/00lndex.html. Accessed 09 Jan 2020

Pretzsch H (2014) Canopy space filling and tree crown morphology in mixedspecies stands compared with monocultures. For Ecol Manag 327:251-264. https://doi.org/10.1016/j.foreco.2014.04.027

Pretzsch H, Schütze G (2009) Transgressive overyielding in mixed compared with pure stands of Norway spruce and European beech in Central Europe: evidence on stand level and explanation on individual tree level. Eur J For Res 128(2):183-204. https://doi.org/10.1007/s10342-008-0215-9

R Core Team (2019) R: a language and environment for statistical computing. $R$ Foundation for Statistical Computing, Vienna

Ratcliffe S, Holzwarth F, Nadrowski K, Levick S, Wirth C (2015) Tree neighbourhood matters - tree species composition drives diversityproductivity patterns in a near-natural beech forest. For Ecol Manag 335:225234. https://doi.org/10.1016/j.foreco.2014.09.032

Raumonen P, Casella E, Calders K, Murphy S, Åkerbloma M, Kaasalainen M (2015) Massivescale tree modelling from Tls data. ISPRS Ann Photogramm Remote Sens Spat Inf Sci II-3(W4):189-196. https:/doi.org/10.5194/isprsannals-I-3-W4-189-2015

Raumonen P, Kaasalainen M, Åkerblom M, Kaasalainen S, Kaartinen H, Vastaranta M, Holopainen M, Disney M, Lewis P (2013) Fast automatic precision tree models from terrestrial laser scanner data. Remote Sens 5(2):491-520. https:// doi.org/10.3390/rs5020491

Rivas JJC, González JGÁ, Aguirre O, Hernández FJ (2005) The effect of competition on individual tree basal area growth in mature stands of Pinus cooperi Blanco in Durango (Mexico). Eur J For Res 124(2):133-142. https://doi. org/10.1007/s10342-005-0061-y

Rusu RB, Cousins S (2011) 3D is here: point cloud library (PCL). Proc IEEE Int Conf Robot Autom:1-4. https://doi.org/10.1109/ICRA.2011.5980567

Sapijanskas J, Paquette A, Potvin C, Kunert N, Loreau M (2014) Tropical tree diversity enhances light capture through crown plasticity and spatial and temporal niche differences. Ecology 95(9):2479-2492. https://doi.org/10.1 890/13-1366.1

Schröter M, Härdtle W, von Oheimb G (2012) Crown plasticity and neighborhood interactions of European beech (Fagus sylvatica L.) in an old-growth forest. Eur J For Res 131(3):787-798. https://doi.org/10.1007/s10342-011-0552-y

Schwinning S, Weiner J (1998) Mechanisms the degree of size asymmetry determining in competition among plants. Oecologia 113(4):447-455. https://doi.org/10.1007/s004420050397

Shannon CE (1948) A mathematical theory of communication. Bell Syst Tech J 27(1):379-423. https://doi.org/10.1145/584091.584093

Tilman D (1999) The ecological consequences of changes in biodiversity: a search for general principles. Ecology 80(5):1455-1474. https://doi.org/10.23 $07 / 176540$

von Oheimb G, Lang AC, Bruelheide H, Forrester DI, Wäsche I, Yu M, Härdtle W (2011) Individual-tree radial growth in a subtropical broad-leaved forest: the role of local neighbourhood competition. For Ecol Manag 261(3):499-507. https://doi.org/10.1016/j.foreco.2010.10.035

Vosselman G, Maas H-G (2010) Airborne and terrestrial laser scanning. Whittles Publishing, Dunbeath, Caithness

Wetterdienst D (2017) Klimareport Schleswig-Holstein. Offenbach am Main, Germany

Williams LJ, Paquette A, Cavender-Bares J, Messier C, Reich PB (2017) Spatial complementarity in tree crowns explains overyielding in species mixtures. Nat Ecol Evol 1(4):0063. https://doi.org/10.1038/s41559-016-0063

Zambrano J, Fagan WF, Worthy SJ, Thompson J, Uriarte M, Zimmerman JK, Umaña MN, Swenson NG (2019) Tree crown overlap improves predictions of the functional neighbourhood effects on tree survival and growth. J Ecol 107(2):887-900. https://doi.org/10.1111/1365-2745.13075

Zuur AF, leno EN, Walker NJ, Saveliev AA, Smith GM (2009) Mixed effects modelling for nested data. In: Zuur AF, leno EN, Walker NJ, Saveliev AA, Smith GM (eds) Mixed effects models and extensions in ecology with R. Springer, New York, pp 101-142. https://doi.org/10.1007/978-0-387-87458-6_5 